\title{
Correction to: Expanding the phenotype of hypomaturation amelogenesis imperfecta due to a novel SLC24A4 variant
}

\author{
Ulrike Lepperdinger ${ }^{1} \cdot$ Elisabeth Maurer ${ }^{2} \cdot$ Martina Witsch-Baumgartner $^{2} \cdot$ Robert Stigler $^{3} \cdot$ Johannes Zschocke $^{2}$. \\ Adrian Lussi $^{4} \cdot$ Ines Kapferer-Seebacher ${ }^{1}$ (D)
}

Published online: 7 September 2020

(C) Springer-Verlag GmbH Germany, part of Springer Nature 2020

\section{Correction to: Clinical Oral Investigations https://doi.org/10.1007/s00784-020-03222-7}

In the pedigree, one of the individuals was marked as unaffected whereas it is heterozygous for the SLC24A4 mutation. Therefore figure 1 has been corrected, as well as the relevant text in the abstract, the results and in the supplements. The fundamental findings of the study are not affected by this error.

Below is the corrected figure 1 .

The online version of the original article can be found at https://doi.org/ 10.1007/s00784-020-03222-7

Ines Kapferer-Seebacher

ines.kapferer@i-med.ac.at

1 Department of Operative and Restorative Dentistry, Medical University of Innsbruck, Anichstraße 35, A-6020 Innsbruck, Austria

2 Division of Human Genetics, Medical University Innsbruck, Innsbruck, Austria

3 Department of Oral and Maxillofacial Surgery, Medical University Innsbruck, Innsbruck, Austria

4 Department of Operative Dentistry and Periodontology, Faculty of Dentistry, University Medical Centre, Freiburg, Germany 


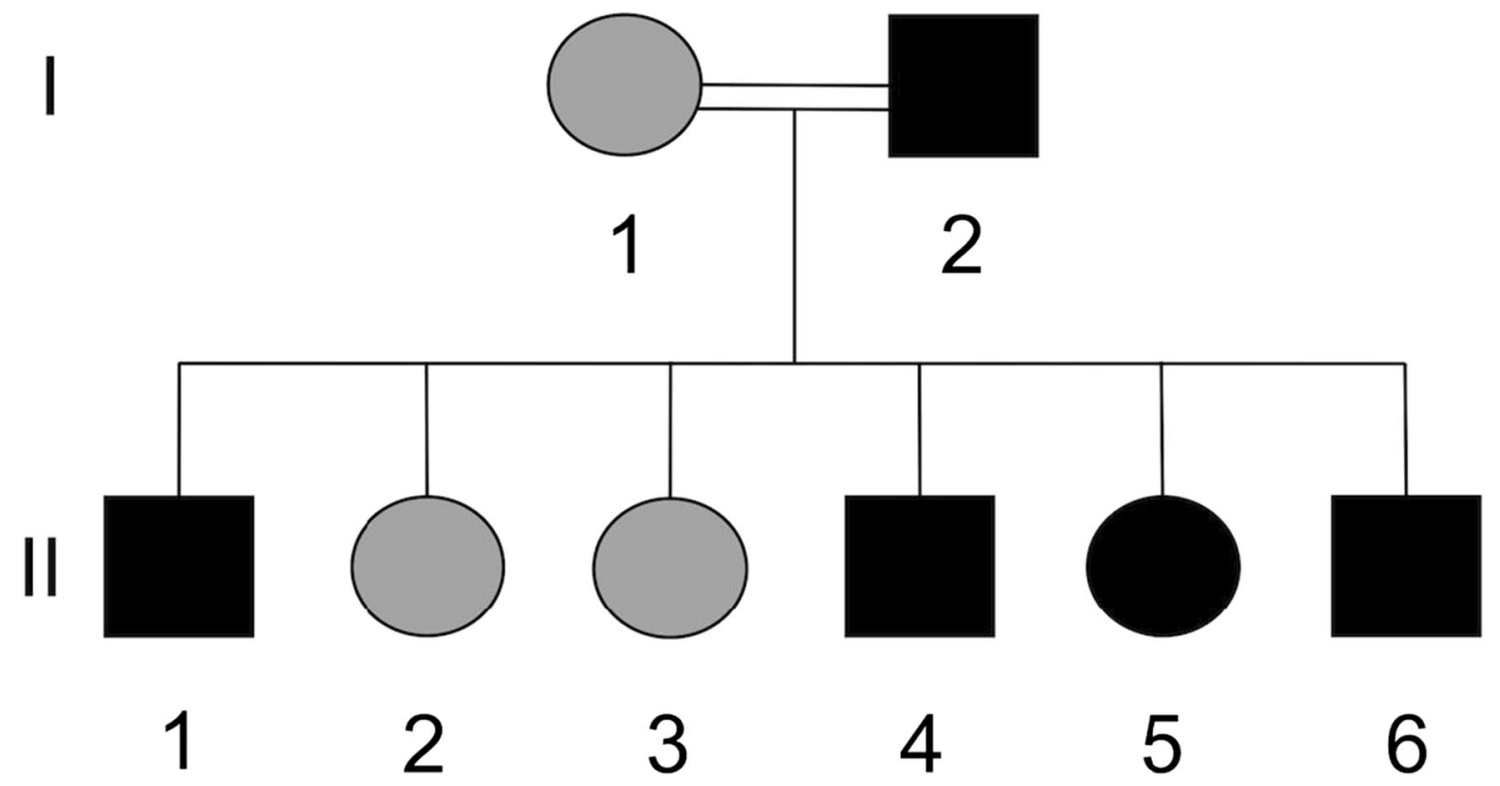

Fig. 1 Pedigree of the family with missense variants c.1604G $>$ A Gray symbols mark individuals with heterozygous missense variants (p.Gly535Asp) in SLC24A4. Symbols: Males are marked as squares and a mild phenotype. White symbols mark clinically nonaffected indiand females as circles. Black symbols mark individuals with homozygous viduals without a variant in SLC24A4

Publisher's note Springer Nature remains neutral with regard to jurisdictional claims in published maps and institutional affiliations. 